\title{
Respon Petani Terhadap Pemanfaatan Kotoran Ternak Sapi Menjadi Pupuk Bokashi Dengan Menggunakan Mikroorganisme Lokal (Mol) Dari Isi Rumen
}

\section{Farmer's Response To The Utilization Of Cow Fattening To Bokashi Fertilizer Using Local Microorganism (Mol) From The Rument Content}

Tri Wahyudi Ariyanto, Raden Agus Triwidodo Saputro, Sunardi

\author{
Politeknik Pembangunan Pertanian Yogyakarta-Magelang \\ Jl. Magelang Kopeng Km 7, Tegalrejo, Magelang \\ email: caknardi762@gmail.com
}

\begin{abstract}
ABSTRAK
Penelitian ini dilakukan 2 Mei 2019 sampai dengan 30 Juni 2019 di Kelompok Tani Sidomukti, Mangunrejo, Tegalrejo, Magelang. Tujuan penelitian untuk mengetahui respon petani terhadap pemanfaatan kotoran ternak sapi menjadi pupuk bokashi mengunakan Microorganisme Lokal (MOL) isi rumen dan mengetahui faktorfaktor internal petani (usia, tingkat pendidikan, pengalaman beternak). Metode pengambilan sampel adalah metode sensus. Variabel yang digunakan adalah variabel independen (umur, tingkat pendidikan, pengalaman beternak) dan variabel dependen (respon petani). Rancangan kajian yaitu menghitung respon petani dengan post test yang berhubungan dengan aspek pengetahuan, sikap dan keterampilan, dan menghitung hubungan antara faktor internal dengan respon petani. Desain yang digunakan One-Shot Case Study yaitu dilakukan pada satu kelompok diberi penyuluhan kemudian dilakukan pengukuran dengan post test. Data meliputi data primer dan sekunder. Data yang telah ditabulasi, dihitung menggunakan skala likert untuk mengukur aspek pengetahuan, sikap dan keterampilan. Metode analisis untuk mengetahui respon petani menggunakan analisis deskriptif dan analisis statistik korelasi rank spearman untuk mengetahui faktor-faktor yang berhubungan dengan respon. Hasil penelitian didapatkan nilai respon petani 1622 termasuk kriteria tinggi terdiri dari aspek pengetahuan 956 termasuk dalam kriteria tahu, sikap 490 termasuk kriteria setuju dan keterampilan 177 termasuk kriteria cukup terampil. Faktor-faktor internal petani yang berhubungan dengan respon diperoleh hasil hubungan antara umur, pendidikan dan pengalaman beternak dengan respon petani tidak signifikan.
\end{abstract}

Kata Kunci: Respon Petani, Pupuk Bokashi, Mol Isi Rumen, Kotoran Ternak Sapi 


\section{ABSTRACT}

This research was conducted from 2 May 2019 to 30 June 2019 in the Sidomukti Farmers Group, Mangunrejo, Tegalrejo, Magelang. This study aimed to determine farmers' response to the utilization of cattle manure into bokashi fertilizer using Local Microorganisms (MOL) rumen contents and to know the internal factors of farmers (age, level of education, breeding experience). The sampling method is the census method. The variables used are independent variables (age, level of education, the experience of raising livestock), and the dependent variable (farmer response).

The study design is to calculate the response of farmers with a post-test related to aspects of knowledge, attitudes, and skills, and calculate the relationship between internal factors and farmer responses. The design used by the One-Shot Case Study is carried out in one group given counseling and then measured by posttest.

Data includes primary and secondary data. The tabulated data is calculated using a Likert scale to measure aspects of knowledge, attitudes, and skills. The analytical method to determine the response of farmers was descriptive analysis and Spearman rank correlation statistical analysis to identify the factors associated with the response.

The results showed that the response value of 1622 farmers included high criteria consisting of aspects of knowledge 956 included in the criteria of knowledge, attitude 490 including the criteria of agreeing and skills 177 including the criteria of being quite skilled. Farmer's internal factors related to the response obtained the relationship between age, education, and experience of raising livestock with an insignificant response.

Keywords: Farmer Response, Bokashi Fertilizer, Rumen Fill Mol, Cow Manure

\section{PENDAHULUAN}

Penyuluhan adalah proses perubahan sosial, ekonomi dan politik untuk memberdayakan dan memperkuat kemampuan semua agribisnis melalui proses belajar bersama yang partisipatif, agar terjadi perubahan perilaku pada diri setiap individu dan masyarakatnya untuk mengelola kegiatan agribisnisnya yang semakin produktif dan efisien, demi terwujudnya kehidupan yang baik dan semakin sejahtera secara berkelanjutan (Mardikanto, 2009).

Limbah peternakan merupakan sumber pupuk organik yang sangat baik apabila dikelola dengan menggunakan kaidah-kaidah pengolahan pupuk organik, termasuk di dalamnya cara pembuatan pupuk organik. Cara pembuatan pupuk organik bermacammacam, diantaranya menggunakan EM4 dan menggunakan star bio (stardec) (Murbandono, 2000).

Berdasarkan Identifikasi Potensi Wilayah (IPW) yang dilakukan di Desa Mangunrejo Kecamatan Tegalrejo Kabupaten Magelang yang terdiri dari enam dusun dan memiliki populasi ternak sapi mencapai 245 ekor (data terolah 2019).

Permasalahan yang dihadapi petani di Desa Mangunrejo yaitu pemanfaatan kotoran ternak sapi yang belum diolah dengan baik sehingga kurang optimal dari segi kualitas pupuk yang dihasilkan, salah satu cara yang dapat dilakukan adalah dengan 
mengolahnya menjadi pupuk bokashi. Pupuk bokashi sangat menguntungkan karena dapat memperbaiki produktivitas dan kesuburan tanah, selain itu juga akan memberikan keuntungan finansial karena mempunyai daya jual.

Tetapi kotoran ternak sapi tidak dapat langsung dimanfaatkan sebagai pupuk bokashi, selain itu pula kondisi mengubah kotoran ternak sapi menjadi pupuk bokashi juga sangat menentukan, sehingga perlu digunakan biostardec aktivator. Aktivator merupakan bahan yang terdiri dari enzim dan mikroorganisme yang dapat mempercepat proses pengomposan. Tujuan dari digunakannya aktivator ini adalah untuk mempercepat proses pengomposan kotoran ternak sapi sehingga dapat dimanfaatkan sebagai pupuk bokashi.

Hasil pengamatan yang dilakukan di Kelompok Tani Sidomukti di Dusun Miriombo, Mangunrejo, Tegalrejo, Magelang, ditemukan permasalahan belum diketahui respon petani terhadap pemanfaatan kotoran ternak sapi menjadi pupuk bokashi dengan mengunakan Microorganisme Lokal (MOL) dari isi rumen dan belum diketahui faktor-faktor internal petani yang berhubungan dengan respon petani terhadap pemanfaatan kotoran ternak sapi menjadi pupuk bokashi dengan mengunakan Mikroorganisme Lokal (MOL) dari isi rumen.

Berdasarkan

permasalahan tersebut maka dilakukan penelitian: "Respon Petani Terhadap Pemanfaatan Kotoran Ternak Sapi Menjadi Pupuk Bokashi Dengan Mengunakan Mikroorganisme Lokal (MOL) Dari Isi Rumen Di Desa Mangunrejo Kecamatan Tegalrejo".

Berdasarkan permasalahan dapat diduga dengan dilakukan penyuluhan kepada petani dapat sangat tinggi respon terhadap pemanfaatan kotoran ternak sapi sebagai pupuk bokashi menggunakan MOL isi rumen. Diduga umur dan tingkat pendidikan petani signifikan dengan respon petani terhadap pemanfaatan kotoran ternak sapi menggunakan MOL dari isi rumen. Diduga pengalaman beternak signifikan dengan respon petani terhadap pemanfaatan kotoran ternak sapi menggunakan MOL dari isi rumen.

Hilman (2016) mendefinisikan respon sebagai perpaduan tanggapan, reaksi, dan jawaban. Respon dalam arti tersebut bermakna bahwa respon tidak hanya berupa tanggapan saja melainkan juga diikuti oleh kecenderungan untuk bertindak sesuai dengan sikap terhadap objek. Tanggapan tersebut dapat mengarah pada benda, orang, peristiwa, lembaga dan norma tertentu.

\section{MATERI DAN METODE}

Pelaksanaan penelitian dimulai pada tanggal 2 Mei 2019 sampai 30 Juni 2019 di Kelompok Tani Sidomukti Desa Mangunrejo Kecamatan Tegalrejo Kabupaten Magelang Provinsi Jawa Tengah. Alat yang digunakan untuk mendukung penelitian alat tulis, berupa bolpoint dan buku, proyektor, laptop, folder, Kamera, handphone, dokumentasi kegiatan. Kuisioner digunakan sebagai alat ukur.

Rancangan kajian yaitu menghitung respon petani dengan melakukan post test yang meliputi aspek pengetahuan, sikap dan keterampilan dan menghitung hubungan antara umur, tingkat pendidikan dan pengalaman beternak dengan respon petani mengenai penyuluhan pemanfaatan kotoran ternak sapi menjadi pupuk bokashi dengan menggunakan mikroorganisme lokal (MOL) dari isi rumen.

Penetapan instrumen untuk informasi kuantitatif maupun informasi kualitatif tentang karakteristik variabel penelitian secara objektif, dilakukan uji validitas dan reliabilitas instrumen. 
Variabel yang diamati dalam penelitian ini adalah Respon ( $\mathrm{Y}$ ) adalah nilai yang dieroleh dari hasil post test dinyatakan dalam skala likert, Umur (X1) adalah umur responden dari awal kelahiran sampai pada saat dilakukan pengambilan data dalam satuan tahun, Tingkat pendidikan (X2) adalah pendidikan formal yang diselesaikan responden. Tingkat pendidikan diukur dengan skala ordinal dalam jenis pendidikan formal untuk tidak tamat SD (1), SD (2), SLTP (3), SLTA (4) dan Perguruan Tinggi (5). Pengalaman beternak (X3) adalah lamanya responden dalam melakukan kegiatan usaha ternak sapi, dalam satuan tahun. Desain digunakan pengkajian untuk melakukan pengamatan respon petani adalah One Shoot Cast Study. Metode pengumpulan data adalah berkoordinasi dengan penyuluh pertanian, pihak Desa Mangunrejo dan pengurus kelompok tani Sidomukti untuk memperoleh data sekunder. Metode pengumpulan data primer dilakukan wawancara kepada responden secara langsung dengan panduan kuisioner dan observasi, mengamati secara langsung kondisi responden serta kondisi wilayah.

Penyusunan instrumen dengan membuat matrik instrumen yang berisi indikator, standar, kriteria, skor dan alat ukur/pertanyaan kuisioner berdasarkan materi yang disampaikan. Uji reliabilitas dilakukan dengan software Microsoft Excel dan SPSS. Analisis data menggunakan analisis deskriptif untuk mengetahui respon petani dan analisis statistik korelasi Rank Sparman untuk melihat karakteristik internal petani yang berhubungan dengan respon. Teknik analisis data masing-masing variabel dengan membuat pengkategorian dalam garis interval.

\section{Aspek Pengetahuan}

Aspek pengetahuan diukur dari pengetahuan petani tentang pemanfaatan kotoran ternak sapi menjadi pupuk bokashi dengan mengggunakan $\mathrm{MOL}$ dari isi rumen. Cara perhitungannya sebagai berikut:

$$
\text { Nilai interval }=\frac{\text { Nilai tertinggi }- \text { nilai terendah }}{\text { Jumlah kriteria }}
$$

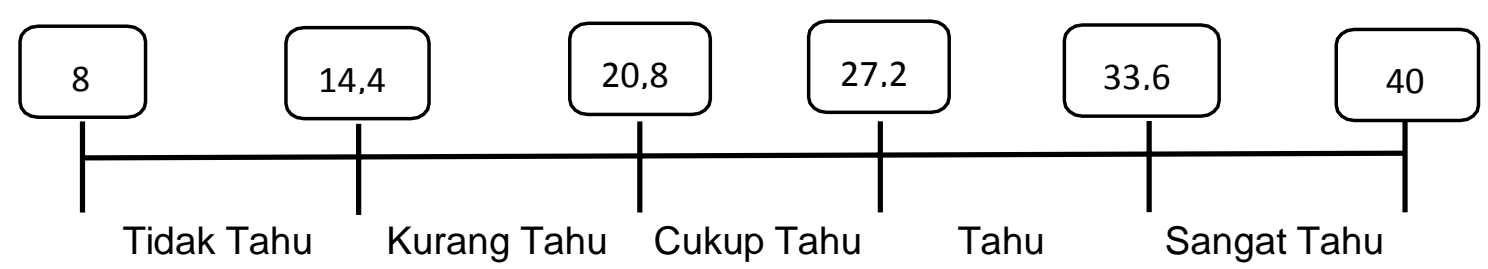

Gambar 3. Garis Kontinum Aspek Pengetahuan

Keterangan:

- Tidak Tahu (TT)

- Kurang Tahu (KT)

- Cukup Tahu (CT)

- Tahu (T)

- Sangat Tahu (ST)

$$
\begin{aligned}
& =8-14,4 \\
& =14,4-20,8 \\
& =20,8-27,2 \\
& =27,2-33,6 \\
& =33,6-40
\end{aligned}
$$




\section{Aspek sikap}

Aspek sikap diukur dari sikap petani tentang pemanfaatan kotoran ternak sapi menjadi pupuk bokashi menggunakan $\mathrm{MOL}$ dari isi rumen. Cara perhitungannya adalah :

$$
\text { Nilai interval }=\frac{\text { Nilai tertinggi }- \text { nilai terendah }}{\text { Jumlah kriteria }}
$$

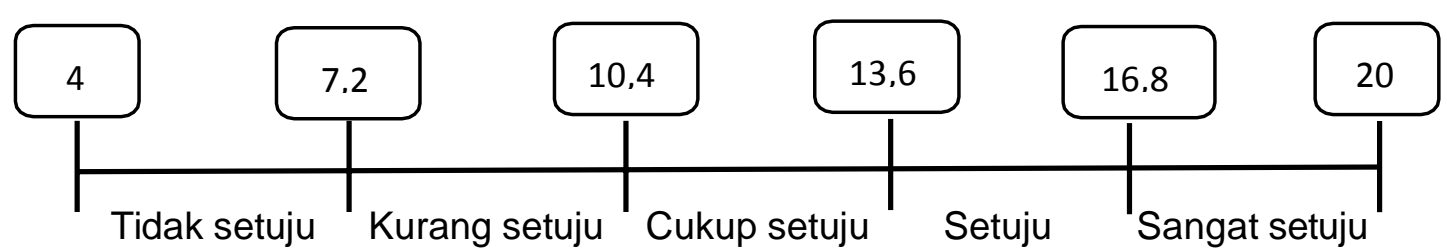

Gambar 4. Garis Kontinum Aspek Sikap

Keterangan :

- Tidak Setuju (TS) $=4-7,2$

- Kurang Setuju (KS) $=7,2-10,4$

- Cukup Setuju (CS) = 10,4-13,6

- Setuju (S) $\quad=13,6-16,8$

- Sangat Setuju (SS) $\quad=16,8-20$

\section{Aspek Keterampilan}

Aspek keterampilan diukur dari keterampilan petani tentang menjadi pupuk bokashi menggunakan MOL dari isi rumen. Cara pemanfaatan kotoran ternak sapi perhitungannya adalah :

$$
\text { Nilai interval }=\text { Nilai tertinggi }- \text { nilai terendah }
$$

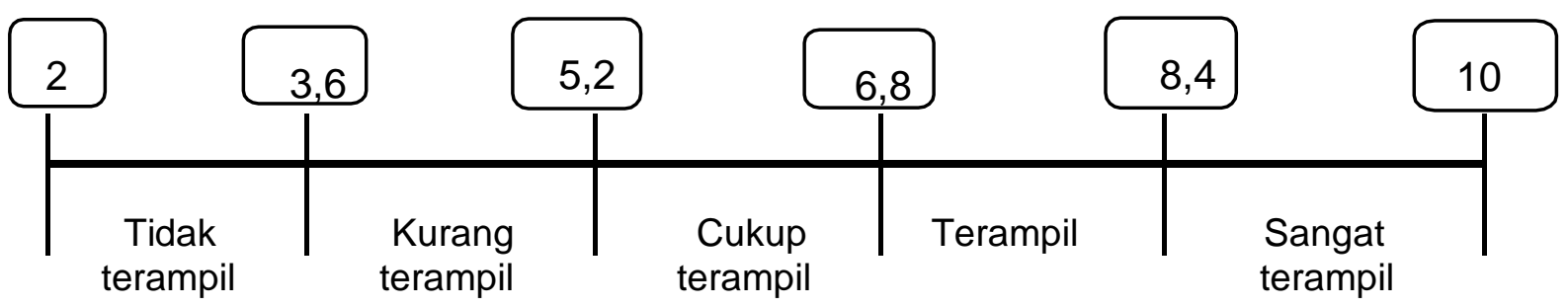

Gambar 5. Garis Kontinum Aspek Keterampilan

Keterangan :

- Tidak Terampil (TT) $=2-3,6$

- Kurang Terampil (KT) $=3,6-5,2$

- Cukup Terampil (CT) $=5,2-6,8$

- Terampil (T) =6,8-8,4

- Sangat Terampil (ST) $=8,4-10$ 


\section{Respon}

Respon diukur dari tiga aspek yaitu aspek pengetahuan, sikap dan keterampilan petani tentang pemanfaatan kotoran ternak sapi menjadi pupuk bokashi menggunakan MOL dari isi rumen. Cara perhitungannya adalah :

$$
\text { Nilai interval }=\frac{\text { Nilai tertinggi }- \text { nilai terendah }}{\text { Jumlah kriteria }}
$$

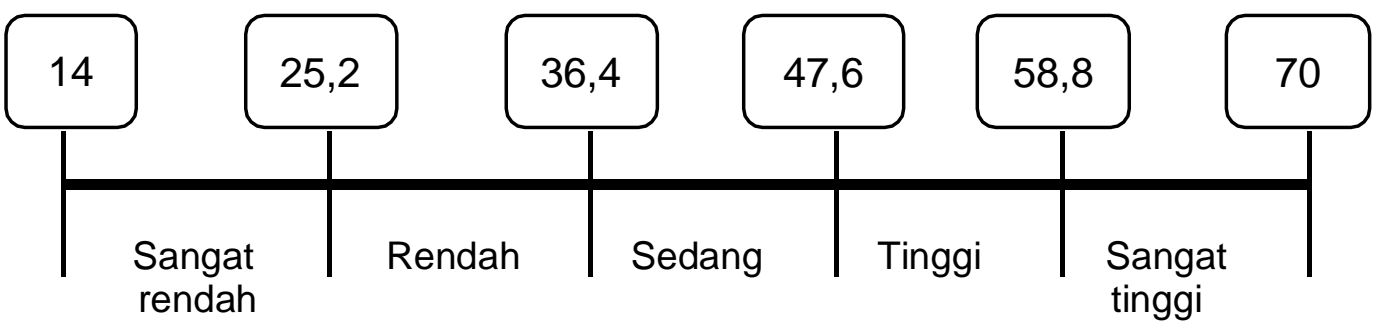

Gambar 6. Garis Kontinum Respon

Keterangan:

- Sangat Rendah (SR) $=14-25,2$

- Rendah (R)

- Sedang (S)

- Tinggi (T)

$$
=25,2-36,4
$$$$
=36,4-47,6
$$

- Sangat Tinggi (ST)

Data kuantitatif dianalisis dengan menggunakan tabel frekuensi dan diagram untuk data awal

responden untuk masing-masing variabel secara tunggal. Uji statistik menggunakan rank spearman korelasi untuk melihat hubungan variabel antara karakteristik internal petani terhadap tingkat kemampuan petani. Data hasil kuesioner diolah dan dirangking serta dilakukan perhitungan korelasi dengan menggunakan rumus korelasi rank spearman menurut Sugiyono (2013) sebagai berikut:

$$
r_{s}=1-\frac{6 \sum d_{i}^{2}}{n\left(n^{2}-1\right)}
$$

Keterangan :

rs : koefisien - korelasi rank spearman

$\mathrm{n}$ : menunjukan jumlah pasangan observasi antara satu variabel terhadap variabel lain.

d : merupakan perbedaan rangking yang diperoleh pada setiap pasangan observasi.

Adapun penjelasan mengenai penafsiran koefisien dapat dilihat pada tabel 2 berikut ini : 
Tabel 2. Nilai Koefisien Korelasi

\begin{tabular}{lr}
\hline \multicolumn{1}{c}{ Nilai Koefisien Korelasi } & Keterangan \\
\hline $0,00-0,199$ & Hubungan Sangat Lemah \\
$0,20-0,0,399$ & Hubungan Lemah \\
$0,40-0,599$ & Hubungan Sedang \\
$0,60-0,799$ & Hubungan Kuat \\
$0,80-1,000$ & Hubungan Sangat Kuat \\
\hline
\end{tabular}

Sumber: Data terolah 2019.

Tujuan pelaksanaan penyuluhan agar petani tahu dan mampu memanfaatkan kotoran ternak sapi yang belum diolah menjadi pupuk bokashi dengan menggunakan MOL dari isi rumen. Sasaran kegiatan penyuluhan adalah anggota Kelompok Tani Sidomukti Mangunrejo, Tegalrejo Kabupaten Magelang.

Persiapan penyuluhan meliputi kuisioner, blangko daftar hadir, peserta dan lembar persiapan menyuluh (LPM). Materi penyuluhan diterapkan berdasarkan hasil identifikasi potensi wilayah (IPW) dan kajian yang dilakukan di Kelompok Tani Sidomukti Desa Mangunrejo. Metode penyuluhan dengan pendekatan perorangan dan kelompok. Pendekatan perorangan dilakukan dengan cara anjangsana ke rumah petani, sedangkan pendekatan kelompok dilakukan dengan cara mengikuti pertemuan kelompok tani yang diadakan setiap satu bulan satu kali.

Teknik penyuluhan yang dilakukan dengan cara ceramah, diskusi dan Tanya jawab kepada Kelompok Tani Sidomukti di Desa Mangunrejo dan diharapkan dengan teknik tersebut materi yang disampaikan dapat diterima, dipahami dan diterapkan oleh petani.

Tujuan penyuluhan agar petani tahu dan mampu memanfaatkan kotoran ternak sapi yang belum diolah menjadi pupuk bokashi dengan menggunakan $\mathrm{MOL}$ dari isi rumen. Sasaran kegiatan penyuluhan adalah anggota Kelompok Tani Sidomukti Mangunrejo Tegalrejo Magelang.

Persiapan penyuluhan meliputi kuisioner, blangko daftar hadir, peserta dan lembar persiapan menyuluh (LPM). Materi penyuluhan diterapkan berdasarkan hasil identifikasi potensi wilayah (IPW) dan kajian yang dilakukan di Kelompok Tani Sidomukti Desa Mangunrejo. Metode penyuluhan dilakukan dengan pendekatan perorangan dan pendekatan kelompok. Pendekatan perorangan dilakukan dengan cara anjangsana kerumah petani, sedangkan pendekatan kelompok dilakukan dengan cara mengikuti pertemuan kelompok tani yang diadakan setiap satu bulan satu kali. Teknik penyuluhan yang dilakukan dengan cara ceramah, diskusi dan tanya jawab kepada Kelompok Tani Sidomukti di Desa Mangunrejo dan diharapkan dengan teknik tersebut materi yang disampaikan dapat diterima, dipahami dan diterapkan oleh petani.

\section{HASIL DAN PEMBAHASAN}

Secara administratif Desa Mangunrejo terletak di Kecamatan Tegalrejo, Kabupaten Magelang. Desa Mangunrejo terdiri dari 6 dusun yaitu Dusun Mangunrejo, Dusun Pangkat, Dusun Garon, Dusun Miriombo, Dusun Paingan, Dan Dusun Ngeren, dengan batas-batas wilayah. Sebelah utara Desa Lebak Kecamatan Grabag, Sebelah timur Desa Gejangan Kecamatan Pakis, Sebelah selatan Desa Kebonagung Kecamatan Tegalrejo, Sebelah barat Desa Donorejo Kecamatan Tegalrejo.

Secara geografis

Desa 
Mangunrejo luas wilayah sebesar 204,465 ha dengan ketinggian wilayah $618 \mathrm{mdpl}$. Jenis tanah adalah Latosol $18,5 \%$ dan Aluvial 14,5\% dengan pH tanah rata-rata $5,5-7$, memiliki intensitas curah hujan rata-rata 161,5 $\mathrm{mm} /$ tahun dengan dengan suhu ratarata $26^{\circ} \mathrm{C}$.

Penduduk Desa Mangunrejo berjumlah 2.243 jiwa dengan penduduk laki-laki sebanyak 1.149 jiwa dan penduduk perempuan sebanyak 1.094 jiwa serta kepala keluarga sebanyak 609 KK dengan 22,29\% atau 500 jiwa, bermata percaharian sebagai petani. Desa Mangunrejo Kecamatan Tegalrejo memiliki luas wilayah sebesar 204,465 ha dengan rincian penggunaannya tersaji pada tabel 4 .

Tabel 4. Luas Penggunaan Wilayah Desa Mangunrejo

\begin{tabular}{lrr}
\hline Uraian & Luas (Ha) & Persentase (\%) \\
\hline Persawahan & 108,685 & 53,15 \\
Perkarangan & 62,53 & 30,58 \\
Tegalan & 32,28 & 15,78 \\
Lain-lain & 0,9 & 0,49 \\
\hline Jumlah & $\mathbf{2 0 4 , 4 6 5}$ & $\mathbf{1 0 0}$ \\
\hline
\end{tabular}

Sumber : Programa Penyuluhan Pertanian Desa Mangunrejo

Berdasarkan tabel diatas, bahwa penggunaan wilayah/lahan di Desa Mangunrejo terbesar adalah sebagai persawahan dengan luas 108,685 $\mathrm{Ha}$ atau sebesar $53,15 \%$ dari luas wilayah desa.

\section{Potensi Pertanian}

Potensi pertanian di Desa Mangunrejo Kecamatan Tegalrejo dapat dilihat pada tabel berikut :

Tabel 5. Produksi Komoditas Pertanian di Desa Mangunrejo

\section{Komoditas}

Padi

Jagung

Cabai

Sumber:

\section{Produksi (ton/ Ha)}

6,4

3,37
Berdasarkan tabel 5 dapat diketahui bahwa komoditas pertanian dengan produksi terbanyak adalah tanaman jagung sebesar 8 ton/ ha.
Potensi Peternakan
Potensi peternakan di Desa Mangunrejo Kecamatan Tegalrejo dapat dilihat pada tabel berikut:

Tabel 6. Populasi Ternak di Desa Mangunrejo

\begin{tabular}{lrc}
\hline \multicolumn{1}{c}{ Komoditas } & Jumlah (ekor) & Persentase (\%) \\
\hline Sapi & 245 & 2,17 \\
Kambing dan Domba & 165 & 1,47 \\
Ayam Kampung & 1.845 & 16,40 \\
Ayam Broiler & 9.000 & 79,96 \\
\hline \multicolumn{1}{c}{ Total } & & $\mathbf{1 0 0 \%}$
\end{tabular}

Sumber : Identifiksi Potensi Wilayah Desa Mangunrejo 
Berdasarkan tabel 6 dapat diketahui komoditas peternakan dengan populasi terbanyak di Mangunrejo adalah ayam broiler sebanyak 9.000 ekor atau $79,96 \%$ dari total populasi ternak.

\section{Kelembagaan Pertanian}

Kelembagaan petani di Desa Mangunrejo di bentuk dalam sebuah kelompok tani sebanyak 6 kelompok tani yaitu kelompok tani Sidomaju, Plamboyan, Barokah, Sidomukti, Sidorahayu, dan Sidodadi yang memiliki sub kelompok ternak bernama Kelompok Ternak Amanah. Semua kelompok tersebut tergabung dalam gabungan kelompok tani Harapan Jaya. Karakteristik responden merupakan penguraian deskripsi identitas responden menurut sampel penelitian yang telah ditetapkan. Tujuan dengan mendeskripsi karakteristik responden adalah memberi gambaran yang menjadi sampel penelitian. Karakteristik responden dalam kajian ini meliputi umur, pendidikan dan pengalaman beternak.

\section{Umur}

Penguraian umur responden dalam kajian ini dapat dilihat pada tabel 7.

Tabel 7. Umur Responden

\begin{tabular}{lcr}
\hline Kelompok Umur & Jumlah (orang) & Persentase (\%) \\
\hline $17-27$ & 1 & 3,33 \\
$28-38$ & 7 & 23,33 \\
$39-49$ & 13 & 43,33 \\
$50-60$ & 8 & 26,67 \\
$61-71$ & 1 & 3,33 \\
\hline Jumlah & $\mathbf{3 0}$ & $\mathbf{1 0 0}$
\end{tabular}

Sumber : Data Primer Terolah 2019

Berdasarkan pengelompokan tersebut diketahui bahwa umur responden petani memiliki rata-rata berkisar antara berumur 39 - 49 tahun sebanyak 13 orang (43,33\%) dan berumur 50 - 60 tahun sebanyak 8 orang $(26,67 \%)$.

Badan Pusat Statistik (BPS) menyatakan bahwa umur produktif penduduk Indonesia adalah 15-64 tahun, BPS membedakan usia produktif menjadi dua, yang pertama usia 15-49 tahun dan usia 50-64 tahun (Badan Pusat Statistik, 2016).

\section{Pendidikan}

Penguraian tingkat pendidikan responden dalam kajian ini dapat dilihat pada tabel 8 .

Tabel 8. Tingkat Pendidikan Responden

\begin{tabular}{lcr}
\hline Pendidikan & Jumlah (orang) & Persentase (\%) \\
\hline SD & 17 & 56,67 \\
SLTP & 11 & 36,67 \\
SLTA & 2 & 6,66 \\
\hline Jumlah & $\mathbf{3 0}$ & $\mathbf{1 0 0 \%}$ \\
\hline
\end{tabular}

Sumber : Data Primer Terolah 2019 
Berdasarkan tabel diketahui bahwa tingkat pendidikan responden rata-rata pada jenjang Sekolah Dasar (SD) sebanyak 17 orang $(56,67 \%)$. Manyamsari \& Mujiburrahmad 2014 menyatakan, pendidikan sangat menentukan tingkat kompetensi petani dalam melakukan kegiatan pertanian.

\section{Pengalaman Beternak}

Penguraian pengalaman beternak responden dalam usaha peternakan dapat dilihat pada tabel 9 :

Tabel 9. Pengalaman Beternak Responden

\begin{tabular}{lcr}
\hline Pengalaman (tahun) & Jumlah (orang) & Persentase (\%) \\
\hline $3-7$ & 7 & 23,33 \\
$8-12$ & 13 & 43,33 \\
$13-17$ & 6 & 20 \\
$18-22$ & 4 & 13,33 \\
\hline Jumlah & $\mathbf{3 1}$ & $\mathbf{1 0 0}$ \\
\hline
\end{tabular}

Sumber : Data Primer Terolah 2019

Berdasarkan tabel 9 bahwa pengalaman responden dalam berusaha ternak sapi rata-rata pada kisaran 8-12 tahun sebanyak 13 orang $(43,33 \%)$. Peternak yang memiliki pengalaman beternak yang cukup lama umumnya memiliki pengetahuan yang lebih banyak dibandingkan peternak yang baru saja menekuni usaha peternakan.

Aspek pengetahuan diukur dari pengetahuan petani tentang pemanfaatan kotoran ternak sapi menjadi pupuk bokashi dengan mengguanakan MOL dari isi rumen dapat dilihat dari tabel 10.

Tabel 10. Nilai Aspek Pengetahuan

\begin{tabular}{|c|c|c|c|c|}
\hline Respon & Nilai post test & Frekuensi (orang) & Persentase & $\%$ \\
\hline Tidak tahu Kurang & 0 & 0 & 0,00 & \\
\hline tahu Cukup tahu & 0 & 0 & 0,00 & \\
\hline Tahu & 157 & 6 & 20,00 & \\
\hline \multirow[t]{2}{*}{ Sangat tahu } & 404 & 13 & 43,33 & \\
\hline & 395 & 11 & 36,67 & \\
\hline Jumlah & 956 & 30 & $100 \%$ & \\
\hline
\end{tabular}

Sumber : Data Primer Terolah 2019

Hasil dilakukannya post test skor yang diperoleh adalah 956, untuk menghitung pengetahuan petani sebagai berikut : Nilai skor tertinggi adalah 5 ( $5 \mathrm{x}$ $8 \times 30=1200$ ), nilai skor terendah adalah $1(1 \times 8 \times 30=240)$. Nilai interval didapat dari (skor tertinggi - skor terendah : kriteria tertinggi) 1200 $-240: 5=192$

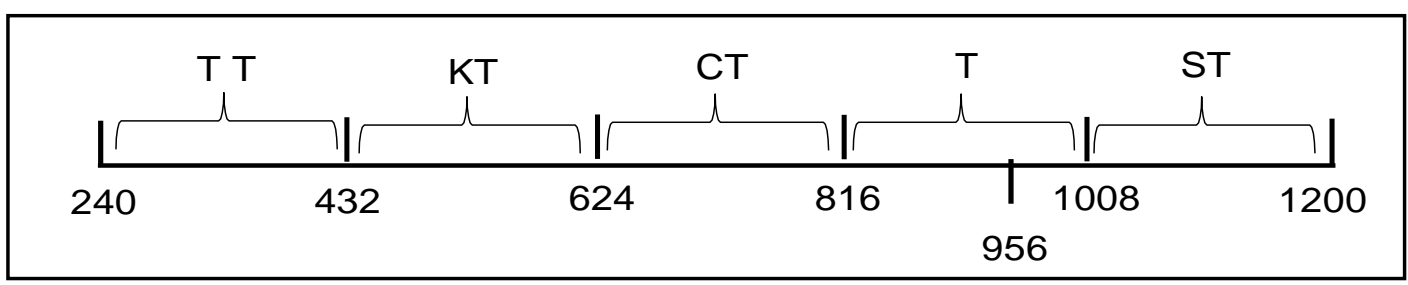

Gambar 7. Garis Kontinum 
Aspek Pengetahuan hasil tabulasi post test yang dicantumkan pada tabel 9 dan garis kontinum responden diperoleh nilai aspek pengetahuan dari 30 responden adalah 956 termasuk kriteria tahu. Menurut pendapat yang dikutip oleh Sardiman (2004), belajar adalah usaha penguasaan materi ilmu pengetahuan yang merupakan sebagian kegiatan menuju tercapainya kepribadian seutuhnya.

Aspek sikap diukur dari sikap petani tentang pemanfaatan pupuk bokashi mengguanakan mol dari isi rumen dapat dilihat dari tabel berikut:

Tabel 10. Nilai Aspek Sikap

\begin{tabular}{lccr}
\hline \multicolumn{1}{c}{ Respon } & Nilai post test & Frekuensi (orang) & Persentase \% \\
\hline Tidak setuju & 0 & 0 & 0,00 \\
Kurang setuju & 0 & 0 & 0,00 \\
Cukup setuju & 0 & 0 & 0,00 \\
Setuju & 283 & 18 & 60,00 \\
Sangat setuju & 206 & 12 & 40,00 \\
\hline \multicolumn{1}{c}{ Jumlah } & $\mathbf{4 8 9}$ & $\mathbf{3 0}$ & $\mathbf{1 0 0 \%}$ \\
\hline
\end{tabular}

Sumber : Data Primer Terolah 2019

Hasil dilakukannya post test skor yang diperoleh adalah 489, untuk menghitung aspek sikap petani sebagai berikut : Nilai skor tertinggi adalah 5 ( $5 \mathrm{x}$ $4 \times 30=600$ ), nilai skor terendah adalah
$1(1 \times 4 \times 30=120)$. Nilai interval didapat dari (skor tertinggi - skor terendah : kriteria tertinggi) $600-120: 5$ $=96$.

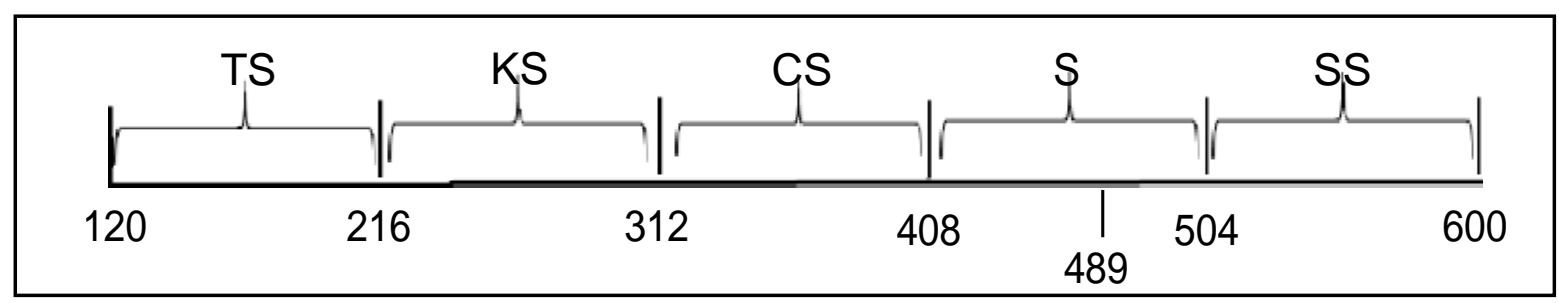

Gambar 8. Garis Kontinum Aspek Sikap

Berdasarkan hasil tabulasi data post test yang dicantumkan pada tabel 10 dan Garis Kontinum responden pada kelompok tani Sidomukti di Desa Mangunrejo Kecamatan Tegalrejo, diketahui nilai aspek sikap dari 30 responden adalah 489 yang mana angka ini termasuk dalam kriteria setuju.

Sikap akan lebih mudah terbentuk apabila pengalaman pribadi terjadi dalam situasi yang melibatkan faktor emosional. Dalam situasi yang melibatkan emosi, penghayatan akan lebih mendalam dan lebih lama berbekas.

Aspek keterampilan petani diukur dari keterampilan petani dalam pembuatan mol isi rumen dan pembuatan pupuk bokashi menggunakan mol dari isi rumen, dapat dilihat dari tabel 12. 
Tabel 12. Nilai Aspek Keterampilan

\begin{tabular}{lccc}
\hline Respon & Nilai post test & Frekuensi (orang) & Persentase \% \\
\hline Tidak terampil & 0 & 0 & 0,00 \\
Kurang terampil & 49 & 10 & 33,33 \\
Cukup terampil & 78 & 13 & 43,33 \\
Terampil & 50 & 7 & 23,34 \\
Sangat terampil & 0 & 0 & 0,00 \\
\hline \multicolumn{1}{c}{ Jumlah } & $\mathbf{1 7 7}$ & $\mathbf{3 0}$ & $\mathbf{1 0 0 \%}$ \\
\hline
\end{tabular}

Sumber : Data Primer Terolah 2019

Hasil post test untuk aspek keterampilan dilakukan secara observasi adalah 177. Perhitungan aspek keterampilan sebagai berikut : Nilai skor tertinggi adalah $5 \times 2 \times 30=300$, nilai skor terendah adalah $1 \times 2 \times 30=60$. Nilai interval didapat dari (skor tertinggi - skor terendah : kriteria tertinggi) 300 $60: 5=48$.

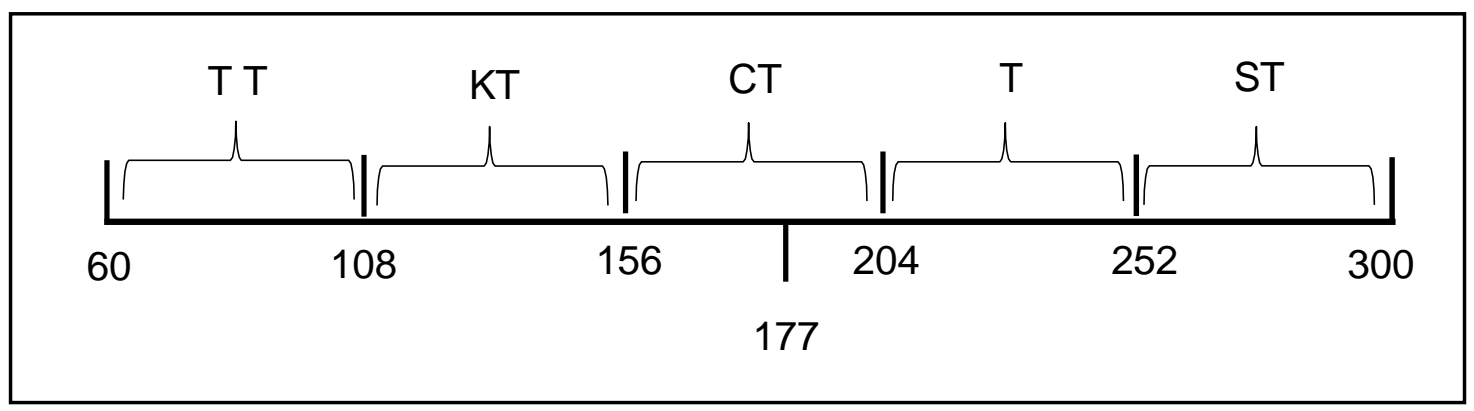

Gambar 9. Garis Kontinum

Aspek Keterampilan berdasarkan hasil tabulasi data post test pada tabel 11 dan Garis Kontinum responden pada Kelompok Tani Sidomukti Mangunrejo Tegalrejo, diketahui nilai aspek keterampilan dari 30 responden adalah 177 termasuk kriteria cukup terampil.

Respon diukur dari tiga aspek yaitu aspek pengetahuan, aspek sikap dan aspek keterampilan petani tentang pemanfaatan kotoran ternak sapi menjadi pupuk bokashi menggunakan mol dari isi rumen. Hasil respon petani terhadap pemanfaatan kotoran ternak sapi menjadi pupuk bokashi menggunakan mokroorganisme lokal (MOL) isi rumen dapat dilihat pada tabel13.

Tabel 13. Nilai Respon

\begin{tabular}{lc}
\multicolumn{1}{c}{ Nilai } & Post test \\
\hline Pengetahuan & 956 \\
Sikap Keterampilan & 489 \\
& 177 \\
\hline Jumlah & $\mathbf{1 . 6 2 2}$
\end{tabular}

Sumber : Data Terolah, 2019

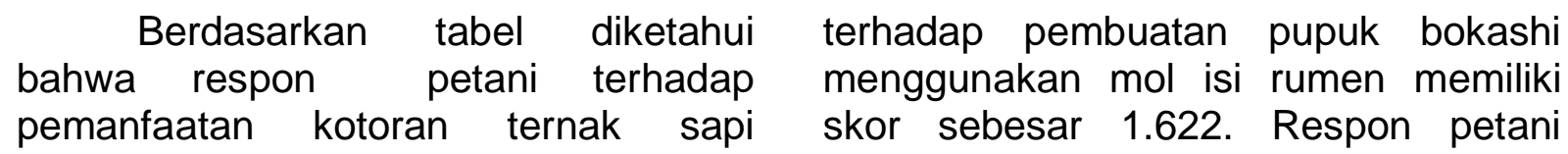


dihitung dari nilai interval adalah nilai tertinggi $5 \times 14 \times 30=2100$, nilai terendah $1 \times 14 \times 30=420$. Nilai tertinggi
- nilai terendah : kriteria tertinggi (2100 $420: 5=336$ ).

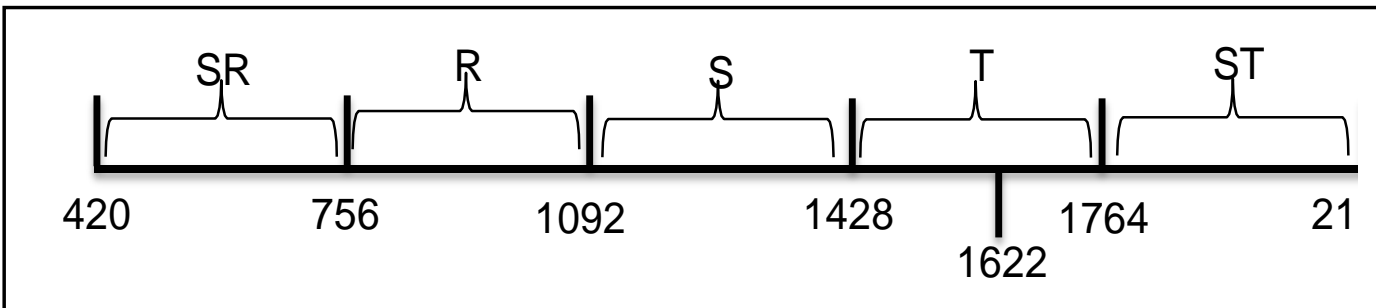

Gambar 10. Garis Kontinum Respon

Berdasarkan hasil tabulasi data post test yang dicantumkan pada tabel 12 dan garis kontinum responden, diketahui nilai respon dari 30 responden adalah 1622 termasuk dalam kriteria tinggi.

Faktor-faktor yang berhubungan dengan respon petani diantaranya umur, tingkat pendidikan dan pengalaman beternak. Hubungan antara respon petani dengan umur, tingkat pendidikan dan pengalaman beternak dapat dilihat dari tabel 14.

Tabel 14. Hubungan Antara Karakteristik Responden Dengan Respon Petani

\begin{tabular}{|c|c|c|c|c|c|c|}
\hline & & & Respon & Umur & Pendidikan & $\begin{array}{c}\text { Pengalaman } \\
\text { beternak }\end{array}$ \\
\hline $\begin{array}{l}\text { Spea } \\
\text { rman }\end{array}$ & Respon & $\begin{array}{l}\text { Correlation } \\
\text { Coefficient }\end{array}$ & 1.000 & -.175 & .227 & .055 \\
\hline $\begin{array}{l}\text { 's } \\
\text { rho }\end{array}$ & & $\begin{array}{l}\text { Sig. }(2- \\
\text { tailed) }\end{array}$ & & .354 & .229 & .773 \\
\hline & & $\mathrm{N}$ & 30 & 30 & 30 & 30 \\
\hline & Umur & Correlation & -.175 & 1.000 & -.210 & $.578^{\star \star}$ \\
\hline & & $\begin{array}{l}\text { Coefficient } \\
\text { Sig. (2- } \\
\text { tailed) }\end{array}$ & .354 & & 265 & .001 \\
\hline & & $\mathrm{N}$ & 30 & 30 & 30 & 30 \\
\hline & Pendidikan & $\begin{array}{l}\text { Correlation } \\
\text { Coefficient }\end{array}$ & .227 & -.210 & 1.000 & .103 \\
\hline & & $\begin{array}{l}\text { Sig. (2- } \\
\text { tailed) }\end{array}$ & .229 & .265 & . & .587 \\
\hline & & $\mathrm{N}$ & 30 & 30 & 30 & 30 \\
\hline & Pengalaman. & Correlation & .055 & $.578^{\star \star}$ & .103 & 1.000 \\
\hline & beternak & $\begin{array}{l}\text { Coefficient } \\
\text { Sig. (2- } \\
\text { tailed) }\end{array}$ & .773 & .001 & .587 & . \\
\hline & & $\mathrm{N}$ & 30 & 30 & 30 & 30 \\
\hline
\end{tabular}

**. Correlation is significant at the 0.01 level (2-tailed).

Sumber : Data Terolah, 2019 
Berdasarkan tabel 14, hubungan antara umur dan respon petani negatif, semakin tinggi umur petani maka semakin rendah respon petani. Dilihat dari sig. (2-tailed) $(P)$ dengan nilai 0,354 menunjukkan hubungan yang tidak signifikan (sig 2-tailed $=0.354>0.05$ ). Jika dilihat dari koefisien korelasi, memiliki keeratan yang sangat lemah atau $(r)=-0,175$.

Berdasarkan tabel 14, hubungan antara pendidikan dan respon petani menunjukkan arah hubungan positif, semakin tinggi pendidikan petani maka semakin tinggi respon petani. Dilihat dari sig. (2-tailed) (P) dengan nilai 0,229 menunjukkan hubungan yang tidak signifikan (sig 2-tailed =0,229>05). Jika dilihat dari koefisien korelasi memiliki keeratan yang lemah atau $(r)=0,227$. Sukardi (2012), mengemukakan bahwa hubungan pendidikan dengan produktivitas kerja akan tercermin dari tingkat pendidikan dan penghasilan yang tinggi, menyebabkan produktivitas kerja yang lebih baik pula dan penghasilan yang diperoleh juga tinggi. Secara umum tingkat pendidikan tinggi, produktivitasnya juga akan tinggi karena rasional dalam berfikir dibanding dengan yang tingkat pendidikan rendah sulit untuk mengadopsi inovasi baru dan relatif bimbang dalam mangambil keputusan.

Berdasarkan tabel 14, hubungan antara pengalaman beternak dan respon petani menunjukkan arah hubungan positif, semakin tinggi pengalaman beternak maka responnya semakin tinggi. Dilihat dari sig. (2-tailed) (P) dengan nilai 0,773 menunjukkan hubungan yang tidak signifikan (sig 2tailed $=0,773>0,05)$. Jika dilihat dari koefisien korelasi memiliki keeratan yang sangat lemah atau $(r)=0,055$. Hal ini didukung oleh pendapat Soekartawi (2005), Pengalaman beternak merupakan suatu hal yang sangat mendasari seseorang dalam mengembangkan usahanya dan sangat berpengaruh terhadap keberhasilan usaha. Peternak yang telah pengalaman beternak akan lebih terampil dan cenderung menghasilkan suatu hasil yang lebih baik daripada peternak yang belum berpengalaman.

Pelaksanaan

penyuluhan dilakukan pada tanggal 13 Mei 2019 yang bertempat di Kelompok Tani Sidomukti yang dihadiri oleh 30 responden terdiri dari petani dan peternak Desa Mangunrejo. Hal ini didukung oleh pendapat Husna (2013) bahwa sasaran penyuluhan yang secara langsung terlibat dalam kegiatan bertani dan pengelolaan usahatani dan secara bersama- sama terlibat dalam pengambilan keputusan terakhir tentang segala sesuatu. Materi yang disampaikan adalah mengenai pemanfaatan kotoran ternak sapi menjadi pupuk bokashi dengan menggunakan MOL dari isi rumen, pembuatan $\mathrm{MOL}$ isi rumen, manfaat pupuk bokashi, manfaat MOL isi rumen dan cara pembuatan pupuk bokasi dan juga cara pembuatan MOL isi rumen.

Teknik penyuluhan melalui ceramah, diskusi dan demcar tentang pemanfaatan kotoran ternak sapi menjadi pupuk bokasi dengan menggunakan MOL dari isi rumen. Hal ini disesuaikan dengan pendapat dari Kusnadi (2011) menyatahan bahwa teknik penyuluhan pertanian dapat didefinisikan sebagai keputusankeputusan yang dibuat oleh sumber atau penyuluh dalam memilih serta menata simbul dan isi pesan menentukan pilihan cara dan frekuensi penyampaian pesan serta menetukan bentuk penyajian pesan. Alat dan bahan yang digunakan dalam kegiatan penyuluhan adalah folder, laptop dan proyektor.

\section{KESIMPULAN}

Berdasarkan penelitian di Kelompok Tani Sidomukti Mangunrejo 
Tegalrejo Kabupaten Magelang dapat disimpulkan:

1 Respon petani dari aspek pengetahuan dengan nilai skor 956 termasuk kategori tahu, aspek sikap dengan nilai skor 489 termasuk kategori setuju dan aspek keterampilan dengan nilai 177 termasuk cukup terampil. Nilai respon didapat dari penjumlahan total nilai skor dari aspek pengetahuan, aspek sikap dan aspek keterampilan dengan nilai 1622 termasuk kategori tinggi.

2. Hubungan antara umur dengan respon petani adalah $(-0,175)$ dan tidak signifikan $0,354, \quad(P>0,05)$, hubungan antara tingkat pendidikan dengan respon petani adalah $(0,227)$ dan tidak signifikan 0,229, $(P>0,05)$ dan hubungan antara pengalaman beternak dengan respon petani adalah $(0,055)$ dan tidak signifikan 0,773 , $(P>0,05)$. Hal ini menunjukan bahwa faktor-faktor internal petani tidak berhubungan secara nyata dengan respon petani terhadap pemanfaatan kotoran ternak sapi menjadi pupuk bokashi dengan menggunakan mikroorganisme lokal (MOL) dari isi rumen.

Berdasarkan hasil penelitian ini, dapat disarankan bahwa Petani diharapkan mampu memanfaatkan kotoran ternak sapi yang sangat berpotensi untuk diolah menjadi pupuk bokashi menggunakan MOL dari isi rumen untuk mendukung usaha taninya, dan perlu adanya tidak lanjut pengkajian dan pembinaan dari instansi terkait tentang penyuluhan pemanfaatan kotoran ternak sapi menjadi pupuk bokashi menggunakan MOL dari isi rumen.

\section{DAFTAR PUSTAKA}

Badan Pusat Statistik. 2013. Statistik Penduduk Lanjut Usia. Jakarta: BPS.
Hilman. 2016. Respon Anggota Kelompok Tani Terhadap Program Pengembangan Usaha Agribisnis Perdesaan (Puap) Di Kecamatan Kebun Tebu Kabupaten Lampung Barat. Fakultas Pertanian Universitas Lampung Bandar Lampung. Diakses 20 Februari 2019.

Husna. 2013. Unsur-unsur penyuluhan pertanian. Diakses 5 Juli 2019. http://jejakpenyuluh.blogspot.com /2013.10/unsur-unsurpenyuluhanpertanian.html

Kusnadi, D. 2011. Metode penyuluhan pertanian. Diakses 1 Maret 2019. http://stppbogor.ac.id.

Manyamsari I, Mujiburrahmad. 2014. Karakteristik petani dan hubungannya dengan kompetensi petani lahan sempit. Dikutip dari jurnal Indah Novita Dewi, San Afri Awang, Wahyu Andayani, \& Priyono Suryanto. Jurnal IImu Kehutanan. Diakses 4 Juli 2019. https://jurnal.ugm.ac.id/jikfkt

Mardikanto, T. 2009. Sistem Penyuluhan Pertanian. Sebelas Maret University Press, Surakarta. Diakses 20 February 2019.

Murbandono, L.H.S. 2000. Membuat Kompos. Penebar Swadaya, Jakarta. Diakse s1 February 2019.

https://books.google.co.id/books?i $d=6$ LOI_x1L_QoC\&printsec=front cover\& $\bar{h} l=i d \&$ source $=g b s \_b o o k \_0$ ther_versions $\# v=$ onepage $\& q \& f=f$ alse

Sardiman, A.M. 2004. Interaksi dan Motivasi Belajar Mengajar. Jakarta: RajaGrafindo Persada. Diakses 4 Juli 2019.

Soekartawi. 2005. Agribisnis Teori \& Aplikasinya. PT Raja Grafindo Persada. Jakarta. Diakses 3 Maret 2019.

Sugiyono. 2012. Metode Penelitian Bisnis: Pendekatan Kuantitatif Kualitatif dan R\&D. Bandung: 

Alfabeta. Diakses 5
Maret 2019.
https://media.neliti.com/media/pu
blications/36066-ID-pengaruh-
perceived-organizational-support-
terhadap-corporate-
entrepreneurship-pa.pdf 2013. pengertian
purposive sampling (2013:218-
219). Diakses 5 Maret 2019. 2013. Metode Penelitian
Bisnis. Bandung: Alfabeta.
Diakses 3 Maret 2019.
https://journal.uc.ac.id/index.php/ performa/article/download/441/39 4

Sukardi. 2012. Faktor-Faktor yang Mempengaruhi Motivasi Peternak dalam Usaha Peternakan Kambing di Kecamatan Tamalatea Kabupaten Jeneponto. Skripsi. Fakultas Peternakan Universitas Hasanuddin Makassar. Diakses 3 Maret 2019.

Winarni. 2003. Komunikasi Massa, Malang UMM Press. Diakses 20 February 2019. http://digilib.uinsby.ac.id/8440/4/B ab2.pdf 